\title{
Psychometric characteristics of the Spanish version of instruments to measure neck pain disability
}

Francisco M Kovacs*1, Joan Bagó ${ }^{2}$, Ana Royuela ${ }^{3}$, Jesús Seco ${ }^{4}$ Sergio Giménez ${ }^{5}$, Alfonso Muriel ${ }^{3}$, Víctor Abraira ${ }^{3}$, José Luis Martín ${ }^{6}$, José Luis Peña ${ }^{7}$, Mario Gestoso ${ }^{8}$, Nicole Mufraggi ${ }^{8}$, Montserrat Núñez $^{9}$, Josep Corcoll10, Ignacio Gómez-Ochoa11, Ma José Ramírez ${ }^{12}$, Eva Calvo ${ }^{12}$, Ma Dolores Castillo ${ }^{13}$, David Martí14, Salvador Fuster ${ }^{9}$, Carmen Fernández ${ }^{15}$, Nuria Gimeno ${ }^{14}$, Alejandro Carballo ${ }^{14}$, Álvaro Milán ${ }^{5}$, Dolores Vázquez ${ }^{16}$, Montserrat Cañellas ${ }^{17}$, Ricardo Blanco ${ }^{7}$, Pilar Brieva ${ }^{12}$, Ma Trinidad Rueda ${ }^{6}$, Luis Álvarez ${ }^{18}$, María Teresa Gil del Real1 ${ }^{1}$ Joaquín Ayerbe ${ }^{19}$, Luis González ${ }^{20}$, Leovigildo Ginel ${ }^{21}$, Mariano Ortega ${ }^{22}$, Miryam Bernal23, Gonzalo Bolado23, Anna Vidal14, Ana Ausín 24, Domingo Ramón ${ }^{24}$, María Antonia Mir25, Miquel Tomás ${ }^{26}$, Javier Zamora ${ }^{3}$ and Alejandra Cano ${ }^{3}$

\footnotetext{
Address: ${ }^{1}$ Departamento Científico, Fundación Kovacs, Palma de Mallorca, Spain, ${ }^{2}$ Unidad de Cirugía del Raquis, Hospital Vall d'Hebrón, Barcelona, Spain, ${ }^{3}$ Unidad de Bioestadística Clínica, Hospital Ramón y Cajal, Madrid, Spain, ${ }^{4}$ Departamento de Enfermería y Fisioterapia, Universidad de León, Ponferrada, Spain, ${ }^{5}$ Centro de Salud del Limonar, Málaga, Spain, ${ }^{6}$ Servicio de Medicina Preventiva, Hospital de Rehabilitación y Traumatología Virgen de las Nieves, Granada, Spain, 7 Servicio de Reumatología, Hospital Marqués de Valdecilla, Santander, Spain, ${ }^{8}$ Clínica Kovacs, Fundación Kovacs, Palma de Mallorca, Spain, ${ }^{9}$ Servicio de Cirugía Ortopédica y Traumatología, Hospital Clínico, Barcelona, Spain, ${ }^{10}$ Centro de Salud de Tramuntana Esporlas, Mallorca, Spain, ${ }^{11}$ Servicio de Rehabilitación, Hospital Lozano Blesa, Zaragoza, Spain, ${ }^{12}$ Unidad de Rehabilitación, Hospital Marqués de Valdecilla, Santander, Spain, ${ }^{13}$ Delegación Asuntos Sociales, Granada, Spain, ${ }^{14}$ Servicio de Traumatología y Ortopedia, Hospital Parc Taulí de Sabadell, Barcelona, Spain, ${ }^{15}$ Centro de Salud de Valldargent, Palma de Mallorca, Spain, ${ }^{16}$ Servicio de Rehabilitación, Mutua Asepeyo, Madrid, Spain, ${ }^{17}$ Servicio de Anestesia, Hospital Parc Taulí de Sabadell, Barcelona, Spain, ${ }^{18}$ Servicio de Traumatología, Fundación Jiménez Díaz, Madrid, Spain, ${ }^{19}$ Servicio de Neurocirugía, Fundación Jiménez Díaz, Madrid, Spain, 20 Centro de Salud Serrería II, Valencia, Spain, ${ }^{21}$ Centro de Salud de Ciudad Jardín, Málaga, Spain, ${ }^{22}$ Centro de Salud de Es Trencadors de Lluchmajor, Mallorca, Spain, ${ }^{23}$ Servicio de Rehabilitación, Hospital Clínico Universitario, Valladolid, Spain, ${ }^{24}$ Unidad Básica de Es Castell, Menorca, Spain, ${ }^{25}$ Centro de Salud de Inca. Mallorca, Spain and ${ }^{26}$ Servicio de Emergencias 061. Mallorca, Spain

Email: Francisco M Kovacs* - kovacs@kovacs.org; Joan Bagó - 13811jbg@comb.es; Ana Royuela - ana.royuela@hrc.es; Jesús Seco - jesus.seco@unileon.es; Sergio Giménez - sgimenez@semergen.es; Alfonso Muriel - kovacs@kovacs.org; Víctor Abraira - kovacs@kovacs.org; José Luis Martín - kovacs@kovacs.org; José Luis Peña - kovacs@kovacs.org; Mario Gestoso - kovacs@kovacs.org; Nicole Mufraggi - kovacs@kovacs.org; Montserrat Núñez - kovacs@kovacs.org; Josep Corcoll - kovacs@kovacs.org; Ignacio Gómez-Ochoa - kovacs@kovacs.org; Ma José Ramírez - kovacs@kovacs.org; Eva Calvo - kovacs@kovacs.org; Ma Dolores Castillo - kovacs@kovacs.org; David Martí - kovacs@kovacs.org; Salvador Fuster - kovacs@kovacs.org; Carmen Fernández - kovacs@kovacs.org; Nuria Gimeno - kovacs@kovacs.org; Alejandro Carballo - kovacs@kovacs.org; Álvaro Milán - kovacs@kovacs.org; Dolores Vázquez - kovacs@kovacs.org; Montserrat Cañellas - kovacs@kovacs.org; Ricardo Blanco - kovacs@kovacs.org; Pilar Brieva - kovacs@kovacs.org; Ma Trinidad Rueda - kovacs@kovacs.org; Luis Álvarez - kovacs@kovacs.org; María Teresa Gil del Real - kovacs@kovacs.org; Joaquín Ayerbe - kovacs@kovacs.org; Luis González - kovacs@kovacs.org; Leovigildo Ginel - kovacs@kovacs.org; Mariano Ortega - kovacs@kovacs.org; Miryam Bernal - kovacs@kovacs.org; Gonzalo Bolado - kovacs@kovacs.org; Anna Vidal - kovacs@kovacs.org; Ana Ausín - kovacs@kovacs.org; Domingo Ramón - kovacs@kovacs.org; María Antonia Mir - kovacs@kovacs.org; Miquel Tomás - kovacs@kovacs.org; Javier Zamora - kovacs@kovacs.org; Alejandra Cano - kovacs@kovacs.org

* Corresponding author
}

Published: 9 April 2008

BMC Musculoskeletal Disorders 2008, 9:42 doi:10.1 186/I47/-2474-9-42
Received: 20 December 2007

Accepted: 9 April 2008 
This article is available from: http://www.biomedcentral.com/I47I-2474/9/42

(c) 2008 Kovacs et al; licensee BioMed Central Ltd.

This is an Open Access article distributed under the terms of the Creative Commons Attribution License (http://creativecommons.org/licenses/by/2.0), which permits unrestricted use, distribution, and reproduction in any medium, provided the original work is properly cited.

\begin{abstract}
Background: The NDI, COM and NPQ are evaluation instruments for disability due to NP. There was no Spanish version of NDI or COM for which psychometric characteristics were known. The objectives of this study were to translate and culturally adapt the Spanish version of the Neck Disability Index Questionnaire (NDI), and the Core Outcome Measure (COM), to validate its use in Spanish speaking patients with non-specific neck pain (NP), and to compare their psychometric characteristics with those of the Spanish version of the Northwick Pain Questionnaire (NPQ).
\end{abstract}

Methods: Translation/re-translation of the English versions of the NDI and the COM was done blindly and independently by a multidisciplinary team. The study was done in 9 primary care Centers and 12 specialty services from 9 regions in Spain, with $22 \mathrm{I}$ acute, subacute and chronic patients who visited their physician for NP: 54 in the pilot phase and 167 in the validation phase. Neck pain (VAS), referred pain (VAS), disability (NDI, COM and NPQ), catastrophizing (CSQ) and quality of life (SF-12) were measured on their first visit and 14 days later. Patients' self-assessment was used as the external criterion for pain and disability. In the pilot phase, patients' understanding of each item in the NDI and COM was assessed, and on day I test-retest reliability was estimated by giving a second NDI and COM in which the name of the questionnaires and the order of the items had been changed.

Results: Comprehensibility of NDI and COM were good. Minutes needed to fill out the questionnaires [median, (P25, P75)]: NDI. 4 (2.2, 10.0), COM: 2.1 (I.0, 4.9). Reliability: [ICC, $(95 \% \mathrm{Cl})$ ]: NDI: $0.88(0.80,0.93)$. COM: $0.85(0.75,0.9 \mathrm{I})$. Sensitivity to change: Effect size for patients having worsened, not changed and improved between days I and I5, according to the external criterion for disability: NDI: $-0.24,0.15,0.66$; NPQ: $-0.14,0.06,0.67$; COM: $0.05,0.19,0.92$. Validity: Results of NDI, NPQ and COM were consistent with the external criterion for disability, whereas only those from NDI were consistent with the one for pain. Correlations with VAS, CSQ and SF12 were similar for NDI and NPQ (absolute values between 0.36 and 0.50 on day I, between 0.38 and 0.70 on day 15), and slightly lower for COM (between 0.36 and 0.48 on day I, and between 0.33 and $0.6 \mathrm{I}$ on day 15). Correlation between NDI and NPQ: $r=0.84$ on day I, $r=0.9$ I on day 15. Correlation between COM and NPQ: $r=0.63$ on day $I, r=0.7 \mathrm{I}$ on day 15 .

Conclusion: Although most psychometric characteristics of NDI, NPQ and COM are similar, those from the latter one are worse and its use may lead to patients' evolution seeming more positive than it actually is. NDI seems to be the best instrument for measuring NP-related disability, since its results are the most consistent with patient's assessment of their own clinical status and evolution. It takes two more minutes to answer the NDI than to answer the COM, but it can be reliably filled out by the patient without assistance.

Trial Registration: Clinical Trials Register NCT00349544.

\section{Background}

Mechanical, non-specific or common neck pain (NP) may have an impact on the functional status of the patient, interfering with basic activities such as sleeping or personal care, as well as on many work-related activities. In fact, NP is a common cause of disability and work absenteeism [1].
Although pain may lead to disability, those are two different dimensions that should be assessed separately [2]. In the research environment, reliable and valid instruments to measure NP-related disability are needed to assess the effect of treatment on that variable. In clinical practice, it is important to reliably measure disability since it influences a patient's quality of life, work absenteeism and personal and societal costs. Early monitoring and accurate follow-up of disability are also useful for identifying 
patients at higher risk for chronic disability and for deciding treatment goals and methods at any given time. In order to be recommended, instruments for measuring disability should be accurate and reliable. To be used in practice, these instruments should not reduce consultation time, i.e., they should be simple and easy to score by the physician, and easily understood by the patients, who can answer the questionnaires in the waiting room without assistance.

The Neck Disability Index (NDI) and the Northwich Park Questionnaire are two questionnaires for measuring NPrelated disability $[3,4]$. Both questionnaires derive from the Oswestry Disability Index for measuring low back pain-related disability [5], and were designed to be filled out directly by the patient. They consist of 10 items reflecting activities of daily living or impairments that can be influenced by NP. For each dimension, six possible answers are provided. The patient must mark the answer that better describes his/her current status. Option 1 scores 0 points and represents no limitation for that particular activity, whereas option 6 scores 5 points and represents the maximum possible limitation (Appendix 1). Therefore, the maximum possible score is 50. However, results are usually given as the percentage of that maximum possible score, so the range from best to worst is $0-100$.

Dimensions explored in the NPQ are neck pain intensity, interference of neck pain with sleep, interference with sleep of pins and needles or numbness in the arms at night, duration of symptoms, carrying objects, reading and watching television, working and/or doing housework, social activities, driving and a comparison of current state with the last time the questionnaire was completed [4]. Dimensions explored in the NDI are neck pain intensity, personal care (washing, dressing, etc.), lifting, reading, headache, concentration, work, driving, sleeping and recreation [3]. The NDI is one of the most used scales for measuring NP-related disability, and it has been successfully translated into French [6], Brazilian Portuguese [7], Korean [8], and Turkish [9]. Additionally, a modified Swedish version also exists [10].

The Core Outcome Measure (COM) was first proposed as a set of outcome measures for low back pain patients [11]. An adaptation for neck pain patients was developed later, and has been assessed in patients with common neck pain and in those with whiplash $[12,13]$. It includes the following dimensions: "severity of pain" (questions 1a -on neck pain- and $1 \mathrm{~b}$-on pain referred to the shoulder or arm-), "function" (question 2), "well-being" (question 3), "disability" (question 4), "absenteeism" (question 5) and "satisfaction" (question 6). Each item has 5 possible answers. Answers for items 3 and 6 are ordered from worst to best, while the rest is ordered from best to worst. (Appendix 2) The final score is the mean of the scores for each item, so to obtain it, the order of answers for items 3 and 6 must first be reversed. The final score ranges from 1.0 (best possible state) to 5.0 (worst possible state) [11-13].

However, only a modified Spanish version of the NPQ existed for measuring NP-related disability in Spanish speaking patients [14], and there was no Spanish version of the NDI or COM for which psychometric characteristics were known.

Therefore, the objectives of this study were: 1) To translate into Spanish and culturally adapt the NDI and COM, 2) to validate their use among Spanish neck pain patients, 3) to compare their psychometric characteristics with those of the NPQ.

\section{Methods \\ Study design}

The study was carried out in three phases: the first was translation into Spanish and cultural adaptation of the NDI and COM; the second was a pilot study to assess the comprehensibility and reproducibility of those Spanish versions; and the third was a validation study to determine their metric characteristics and to compare them with those of the NPQ.

\section{Translation phase}

The same methods were followed separately for both the NDI and COM questionnaires. Each questionnaire was translated into Spanish by two different and independent native Spanish speakers, who had no medical knowledge and were both unaware of the purpose of the translation and of the fact that another translator was doing the same task. Both Spanish translations were then compared for inconsistencies. The two translations were then retranslated, also blindly and independently, into English by two native English speakers. Each of the English translations was then compared with the original English questionnaire and checked for inconsistencies.

The Spanish version of the questionnaire was then separately reviewed and fine tuned by a bilingual team including the four translators, eight primary care physicians, four back specialists, and three methodologists (see Additional files 1 and 2).

\section{Pilot phase}

The pilot phase was performed in 15 Centers located in 7 different administrative regions, of the 17 existing in Spain. All the Centers belong to the Spanish National Health System and are involved in the Spanish Back Pain Research Network. Participating Centers included 8 pri- 
mary care centers and 7 hospital outpatient clinics in orthopedic surgery, rheumatology and rehabilitation.

The pilot study was carried out with patients who consulted their physician for NP between Oct 7, 2005, and April 5, 2006. Inclusion criteria were consulting for NP, with or without referred pain, being able to read Spanish and signing the corresponding written informed consent. The study was approved by the Ethics Commission of the Hospital Parc Tauli (Sabadell, Barcelona) on Oct $5^{\text {th }}$, 2005.

Exclusion criteria were: functional illiteracy (mental status insufficient to be able to complete the questionnaires), treated or untreated central nervous system impairment, direct trauma to the neck, and criteria for referral to surgery or for suspecting a potential systemic disease. Criteria for referral to surgery were defined as clinically relevant motor weakness or disabling pain radiating down the arm for at least 6 weeks in spite of conservative treatment, caused by a nerve root compression demonstrated by magnetic resonance (MRI) or computed tomography (CT) studies. Reasons for suspecting a potential underlying systemic disease were defined as oncologic disease during the previous 5 years, constitutional symptoms unexplained weight loss, fever, chills-, history of intravenous drug use, or immunocompromised host.

The sample size of the pilot study was established at 50 patients. According to the available evidence on low back pain patients, the limit between acute and subacute pain was established at 14 days [2,15], and the limit between subacute and chronic at 90 days. ${ }^{16}$

Patients were seen the day of admission to the study (day 1) and 14 days later (day 15). At the first visit, the following variables were recorded on the data collection form: sex, age, socioeconomic level, family situation, academic level, work status, duration of the current work status, chronicity of pain (defined as acute, subacute or chronic) $[2,15,16]$, patients' subjective assessments of severity of pain (no pain, mild, moderate, severe, unbearable) and of degree of limitations in daily living due to neck pain (none, mildly limited, moderately, severely, or very severely limited). Those patients' subjective assessments were considered as the "external criterion" for severity of pain and disability, respectively.

In addition, diagnostic procedures and treatments that patients had undergone were recorded, and those subjects in whom cervical disc herniations had been observed on MRI or CT scans were identified (Table 1).

At both visits, patients were given two separate Visual Analogue Scales (VAS) [17] for measuring neck pain and pain referred to the arm, the NDI, COM and NPQ questionnaires to assess neck pain-related disability, the previously validated Spanish versions of the SF-12 questionnaire for measuring general quality of life [18], and the Coping Strategies Questionnaire (CSQ) $[19,20]$ to assess catastrophizing thoughts. VAS values range from better to worse, from 0 to 10 , and CSQ from 0 to $36[17,19,20]$. Within the SF-12 two subscales are defined: the physical component summary (PCS-SF12) and the mental component summary (MCS-SF12). Higher scores reflect better quality of life, and values have been normalized so that mean values on both subscales for the Spanish population are 50, and SD is 10 . Values range from 19.85 to 56.71 for PCSSF12, and from 14.15 to 68.45 for MCS-SF12 [18].

All self-assessment questionnaires were given by administrative staff and the patients filled them out on their own and alone, without the presence of staff or accompanying persons. Requests for aid in interpretation of the items in the NDI and COM questionnaires were registered. The completed instruments were then given to the treating physician, who stapled scales and questionnaires onto the patient's data collection form.

Patients were told that several questionnaires were going to be given, and were asked to notify the staff in case that any of them was given twice. On day 1 , each patient was given a first NDI and COM questionnaire. The time needed for answering each one was recorded. To assess repeatability, patients were asked to fill out the VAS, RMQ and SF12, and at least $30 \mathrm{~min}$. after having answered the NDI and COM the patient was given a second version of those questionnaires. Questionnaires in this second set were printed in differently colored paper, listed the items in a different order and were not titled "NDI" and "COM", but "NID" and "CSC6". Finally, the clinician filled out a standardized questionnaire asking each patient about his or her interpretation of the meaning of each of the items in the NDI and the COM.

It was decided that sentences for which more than $10 \%$ of patients in the pilot study needed clarification or misinterpreted the meaning would be reviewed before undertaking the validation study. Such review would be made by the bilingual team that developed the first version, based on the patients' suggestions and on the comments from the clinicians administering the questionnaire and interviewing the patients. It was also decided that if that team felt that potential modifications in the questionnaire were relevant enough, data gathered from patients included in the pilot phase would not be used for the objectives of the validation phase.

Data were entered in the database at a centralized coordination office. Entry of data was done independently by 
Table I: Characteristics of study participants.

\begin{tabular}{|c|c|}
\hline Variable; $n(\%)$ & $\begin{array}{c}N(\%) \\
N=221\end{array}$ \\
\hline \multicolumn{2}{|l|}{ Gender: } \\
\hline Female & $172(77.8)$ \\
\hline Male & $49(22.2)$ \\
\hline Age; median (SD) & $48.7(14.8)$ \\
\hline \multicolumn{2}{|l|}{ Recruitment setting } \\
\hline Primary care & $43(19.5)$ \\
\hline Specialized care & $178(80.5)$ \\
\hline Duration of current episode (days); median (P25;P75) & $40.0(15.0 ; 90.0)$ \\
\hline \multicolumn{2}{|l|}{ Chronicity } \\
\hline Acute ( $1-14$ days $)$ & $46(20.8)$ \\
\hline Subacute (14-90 days) & $152(68.8)$ \\
\hline Chronic ( $>90$ days) & $22(10.0)$ \\
\hline Missing & I $(0.5)$ \\
\hline \multicolumn{2}{|l|}{ Family situation } \\
\hline Single & $48(21.7)$ \\
\hline Married & $|3|(59.3)$ \\
\hline Widowed & $19(8.6)$ \\
\hline Divorced & $21(9.5)$ \\
\hline Other & $\mathrm{I}(0.5)$ \\
\hline Missing & $\mathrm{I}(0.5)$ \\
\hline \multicolumn{2}{|l|}{ Academic level } \\
\hline Less than elementary school & $21(9.5)$ \\
\hline Elementary school & 81 (36.7) \\
\hline High school & $74(33.5)$ \\
\hline University & $39(17.6)$ \\
\hline Missing & $6(2.7)$ \\
\hline \multicolumn{2}{|l|}{ Working situation } \\
\hline Self-employed & $23(10.4)$ \\
\hline Employed & $12 \mid(54.4)$ \\
\hline Retired & $34(15.4)$ \\
\hline Without work & $6(2.7)$ \\
\hline Student & $5(2.3)$ \\
\hline Housewife & $24(10.9)$ \\
\hline Missing & $8(3.6)$ \\
\hline \multicolumn{2}{|l|}{ External criterion for neck pain } \\
\hline No pain & $7(3.2)$ \\
\hline Mild pain & $74(33.5)$ \\
\hline Moderate pain & $83(37.6)$ \\
\hline Severe pain & 49 (22.2) \\
\hline Very severe pain & $8(3.6)$ \\
\hline \multicolumn{2}{|l|}{ External criterion for neck disability } \\
\hline None & $7(3.2)$ \\
\hline Mild & $56(25.3)$ \\
\hline Moderate & $82(37.1)$ \\
\hline Severe & $59(26.7)$ \\
\hline Very severe & $16(7.2)$ \\
\hline Missing & $\mathrm{I}(0.5)$ \\
\hline \multicolumn{2}{|l|}{ X-rays } \\
\hline No & $105(47.5)$ \\
\hline Yes & $116(52.5)$ \\
\hline \multicolumn{2}{|l|}{ CT Scan } \\
\hline No & 206 (93.2) \\
\hline Yes & $15(6.8)$ \\
\hline
\end{tabular}


Table I: Characteristics of study participants. (Continued)

\begin{tabular}{|c|c|}
\hline \multicolumn{2}{|l|}{ MRI } \\
\hline No & $176(79.6)$ \\
\hline Yes & 45 (20.4) \\
\hline \multicolumn{2}{|c|}{ Image of cervical disc herniation } \\
\hline No & $177(80.1)$ \\
\hline Yes & $42(19.0)$ \\
\hline Missing & $2(0.9)$ \\
\hline \multicolumn{2}{|c|}{ Electromyography } \\
\hline No & $210(95.0)$ \\
\hline Yes & II (5.0) \\
\hline \multicolumn{2}{|c|}{ Drug Treatment } \\
\hline No & $29(13.1)$ \\
\hline Yes & $192(86.9)$ \\
\hline \multicolumn{2}{|c|}{ Education (traditional biomechanic) } \\
\hline No & $199(90.0)$ \\
\hline Yes & $21(9.5)$ \\
\hline Missing & $\mathrm{I}(0.5)$ \\
\hline \multicolumn{2}{|c|}{ Education (active management) } \\
\hline No & $214(96.8)$ \\
\hline Yes & $7(3.2)$ \\
\hline \multicolumn{2}{|c|}{ Physiotherapy (passive) } \\
\hline No & $182(82.4)$ \\
\hline Yes & 39 (I7.6) \\
\hline \multicolumn{2}{|l|}{ Exercise } \\
\hline No & $196(88.7)$ \\
\hline Yes & $25(11.3)$ \\
\hline \multicolumn{2}{|c|}{ Rehabilitation } \\
\hline No & $208(94.1)$ \\
\hline Yes & $13(5.9)$ \\
\hline \multicolumn{2}{|c|}{ NRT intervention } \\
\hline No & $195(88.2)$ \\
\hline Yes & 26 (II.8) \\
\hline \multicolumn{2}{|c|}{ Epidural injections } \\
\hline No & $219(99.1)$ \\
\hline Yes & $2(0.9)$ \\
\hline \multicolumn{2}{|c|}{ Facet joint denervation } \\
\hline No & $216(97.7)$ \\
\hline Yes & $5(2.3)$ \\
\hline \multicolumn{2}{|l|}{ Surgery } \\
\hline No & $219(99.1)$ \\
\hline Yes & $2(0.9)$ \\
\hline \multicolumn{2}{|c|}{ Other treatments } \\
\hline No & $204(92.3)$ \\
\hline Yes & $17(7.7)$ \\
\hline
\end{tabular}

two administrative assistants, who double-checked that the data they were entering coincided with the scores of the two VAS scales and the NPQ, NDI, NID, COM, CSC6, CSQ, and SF-12 questionnaires.

\section{Validation phase}

The validation phase was performed in 12 Health Care Centers from 7 different regions in Spain, including two regions from which no Center had participated in the pilot phase. Ten Centers belong to the Spanish National Health System (SNHS) and two to not-for-profit Foundations working for SNHS. All the Centers are involved in the Spanish Back Pain Research Network. Participating Centers included 3 primary care centers and 9 specialty centers in rehabilitation, neuroreflexotherapy, orthopedic 
surgery, rheumatology and neurosurgery, five of which did not participate in the pilot phase.

The validation study was carried out with subjects who consulted for neck pain between April 6, 2006 and Feb 1, 2007. In order to ensure a sufficient number of acute, subacute and chronic patients, the sample size was established at 150 with a minimum of 15 in each of the three subgroups (acute, subacute and chronic). The only differences with methods used in the pilot phase were: 1) the time needed to fill out the NDI and COM was not registered, 2) only one version of the questionnaires was given (NID and CSC6 were not used), and 3) patients were not asked about their comprehension of each item in the questionnaires.

\section{Analysis}

Comprehension was determined in the pilot study by the patients' answers to the questions exploring their understanding of each item on the NDI and COM questionnaires, and was measured in both the pilot and validation studies by the patients' requests for aid in interpretation and by the number of items which were not answered in each questionnaire.

The distribution of answers across categories was assessed for each item, and potential ceiling and floor effects were estimated by calculating the percentage of subjects indicating the maximum and minimum possible scores for the NDI, COM and NPQ questionnaires.

Sensitivity to change was estimated by calculating the effect size of NDI, NPQ and COM in patients that, according to external criteria for pain and disability, had worsened, not changed or improved between days 1 and 15 . Worsening and improvement in pain and disability were defined as any negative or positive change in the corresponding external criterion. For each questionnaire, effect size was calculated as the difference between scores on day 1 and 15 , divided by the standard deviation of the score on day 1 . According to this method, an effect size $<0.20$ corresponds to no change, $0.20-0.49$ to a small change, 0.50 to 0.79 to a moderate change and $\geq 0.80$ to a great change [21-23].

Test-retest reliability was measured in the pilot phase, comparing the results of the first and second NDIs, identified respectively as "NDI" and "NID", and the results of the first and second COM, identified respectively as "COM" and "CSC6". Reliability was assessed through the kappa index for answers given to the same items in both versions of each questionnaire. The reliability of the total score was assessed through the intraclass correlation coefficient [24] and the Bland-Altman method [25]. In addition, the total scores of both versions of the NDI were classified as reflecting "no disability" (NDI < $10 \%$ of maximum total score), or a "mild" (NDI between 10\% and < $30 \%$ ), "moderate" (NDI between 30\% and < 50\%), "severe" (NDI between $50 \%$ and $<70 \%$ ) or "very severe" (NDI $>=70 \%$ ) degree of disability [2]. The kappa index was used to compare those total scores. To that end, bisquare weights [26] were used. Since results from the COM are not categorized, this approach was only used for NDI

Cronbach's alpha was used to evaluate internal consistency of the NDI and NPQ [27]. Since COM aggregates several subscales, Cronbach's alfa was calculated only for the subscales on pain and disability of that questionnaire. Validity was measured by Spearman's correlation coefficients between VAS, CSQ, PCS-SF12, MCS-SF12, NPQ, NDI and COM values, for days 1 and 15 [17]. In addition, median (P25, P75) total scores of NDI, COM and NPQ were calculated for each category in the external criteria for pain severity and disability.

\section{Results}

A total of 221 patients were eligible and none were excluded. Fifty-four patients were recruited for the pilot study and 167 for the validation study. Forty-two (19.0\%) showed images of cervical disc herniation on MRI. For the pilot study, 23 patients were recruited from primary care centers and 31 from the hospital setting. For the validation study, 20 patients were recruited from primary care centers and 147 from the hospital setting (Table 1).

Table 1 shows the characteristics of the study subjects and Table 2 shows values for scores on the VAS, NDI, COM, NPQ and SF-12 for days 1 and 15. Since data are slightly skewed, they are given as a median (P25, P75).

The time needed to fill out the Spanish version of the NDI was 4 minutes (P25, P75: 2.2, 10.0), and for the Spanish version of the COM, it was $2.1 \mathrm{~min}$. $(1.0,4.9)$.

In relation to the NDI, at the end of the pilot phase 10 patients had asked for aid in the interpretation of questions No. 3 (4 patients, $7.4 \%$ of those participating in the pilot phase), No. 8 (3 patients, 5.5\%), No. 1 (2 patients, $3.7 \%$ ), No. 2 (2 patients, $3.7 \%$ ) No. 7 (1 patient, 1.9\%) and No. 9 (1 patient, 1.9\%), with 4 patients asking for help with two questions. In addition, 8 patients did not answer question No. 8 because they did not drive. Only four patients misunderstood the meaning of the following questions: $\mathrm{N}^{\circ} 4$ (2 patients, 3.7\%), No. 5 (1 patient, $1.9 \%$ ) and No. 7 (1 patient, 1.9\%).

In relation to the COM, 10 patients asked for aid in interpretation of questions $\mathrm{N}^{\circ} 6$ (4 patients, 7.4\%), No. 5 (4 patients, 7.4\%), No. 4 (3 patients, 5.5\%), No. 3 (2 
Table 2: Values for VAS, NDI, NPQ, COM, CSQ, and SF-I 2*

\begin{tabular}{|c|c|c|c|c|}
\hline & \multicolumn{2}{|c|}{ Day I } & \multicolumn{2}{|c|}{ Day 15} \\
\hline & $\mathrm{n}$ & Value & $\mathrm{n}$ & Value \\
\hline Neck pain (VAS), range $0-10$ & 221 & $6.0(4.0 ; 7.0)$ & 221 & $5.0(3.0 ; 7.0)$ \\
\hline Referred pain (VAS), range $0-10$ & 221 & $4.0(0.0 ; 7.0)$ & 221 & $3.0(0.0 ; 6.0)$ \\
\hline Disability (NDI), range $0-100$ & 221 & $37.5(26.0 ; 51.1)$ & 221 & $31.1(20.0 ; 44.4)$ \\
\hline Disability (NPQ), range $0-100$ & 221 & $38.9(30.5 ; 54.6)$ & 221 & $34.4(20.6 ; 48.6)$ \\
\hline Disability (COM), range $1-5$ & 217 & $2.7(2.4 ; 3.4)$ & 215 & $2.4(1.9 ; 3.0)$ \\
\hline Catastrophizing (CSQ), range $0-36$ & 218 & $12.0(3.0 ; 18.0)$ & 219 & $7.0(0.0 ; 15.0)$ \\
\hline Physical quality of life (PCSF-12), range 19.85 to 56.7 I & 215 & $35.4(30.6 ; 43.0)$ & 214 & $39.0(33.2 ; 48.0)$ \\
\hline Mental quality of life (MCSF-12), range 14.15 to 68.45 & 215 & $41.6(29.7 ; 54.6)$ & 214 & $45.7(31.1 ; 55.0)$ \\
\hline
\end{tabular}

*: Data given as median (P25, P75)

patients, 3.7\%), No. 2 (2 patients, 3.7\%), No. 1b (1 patient, $1.9 \%$ ) and No. 1a (1 patient, $1.9 \%)$, with one patient requesting help with 4 questions, one with 3 questions and three with 2 questions. Only one patient (1.9\%) misunderstood the meaning of question No. 6. Therefore, the wording of the NDI and COM remained unchanged for the validation phase.

No patient notified the staff of having identified the NDI and the NID questionnaires, or the COM and the CSC6, as being the same. Cronbach's alfa was 0.89 for the NDI, 0.91 for the NID, 0.84 for the NPQ, 0.73 and 0.84 for the pain and disability subscales of COM, respectively, and 0.62 and 0.90 for the pain and disability subscales of CSC6, respectively.

In relation to the NDI, a comparison of the scores of both versions of the questionnaire yielded the following results [median (P25; P75)]: NDI: 36.9 (25.6; 51.8), NID: 35.0 $(25.5 ; 46.2)$, with $68.5 \%$ of answers being identical in both questionnaires, and an intraclass correlation coefficient for both of 0.88 (95\% IC; $0.80,0.93)$. The limits of agreement between NDI and NID were $1.25 \pm 18.33$ (see Additional file 3 ). The mean of bi-square weighted kappa values for all items was 0.84 . Six items had a substantial concordance of 0.61-0.80 (Nos. 3, 4, 6, 7, 8 and 10), and four (Nos. 1, 2, 5 and 9) an almost perfect concordance greater than 0.80 [28].

In relation to the COM, a comparison of the scores of both versions of the questionnaire yielded the following results [median (P25; P75)]: COM: $3.0(2.6 ; 3.5)$, CSC6:
$2.8(2.6 ; 3.4)$, with $76.4 \%$ of answers being identical in both questionnaires, and an intraclass correlation coefficient for both of 0.85 (95\% IC; $0.75,0.91)$. One item had a moderate concordance of 0.54 (No. 6), two a substantial concordance of between 0.61 and 0.80 (Nos. 1a and 3), and four (Nos. 1b, 2, 4 and 5) an almost perfect concordance greater than 0.80 [28]. The limits of agreement between COM and CSC6 were $0.04 \pm 0.76$ (see Additional file 3).

All of the items of NDI, NPQ and COM had answers distributed across all categories. For the NDI, the lowest observed score was $4 \%$ (rated by 1 patient, $0.5 \%$ of the 221 subjects participating in the study), and the highest one was $86 \%$ (rated by 1 patient, $0.5 \%$ ). For the COM, the lowest observed score was 1.2 points (rated by 2 patients, $0.9 \%$ ) and the highest one was 5.0 ( 1 patients, $0.5 \%)$. For the NPQ, the lowest observed score was 5.6\% (1 patient, $0.5 \%$ ), and the highest was $84.4 \%$ (1 patient, $0.5 \%$ ) (Table 3).

Results of NDI, NPQ and COM were consistent with the external criterion for disability, so that values for those questionnaires were higher as patient's self-perception of disability increased (Table 5). However, only results of the NDI were consistent with the external criterion for pain (Table 4). For NPQ, values were identical for subjects in the categories "severe pain" and "very severe pain". For COM, values were identical for patients in the "mild pain" and "moderate pain" categories, and were higher for those in the "severe pain" category than for those in the "very severe pain" category (Table 4).

Table 3: Maximum and Minimum Scores: Floor and Ceiling Effects.

\begin{tabular}{|c|c|c|c|c|}
\hline & Minimum Score Recorded & Patients With Minimum Score (Floor Effect) & Maximum Score Recorded & Patients With Maximum Score (Ceiling Effect) \\
\hline NDI & 4.0 & I $(0.5 \%)$ & 86.0 & I (0.5\%) \\
\hline NPQ & 5.6 & $\mathrm{I}(0.5 \%)$ & 84.4 & $\mathrm{I}(0.5 \%)$ \\
\hline COM & 1.2 & $2(0.9 \%)$ & 5.0 & $\mathrm{I}(0.5 \%)$ \\
\hline
\end{tabular}

NDI and NPQ scores are given as \% (range 0-100). COM scores are given as points (range I-5). 
Table 4: Values of NDI, NPQ and COM across categories for external criteria for pain*

\begin{tabular}{|c|c|c|c|c|c|}
\hline External criterion for pain* & No pain & Mild pain & Moderate pain & Severe pain & Very severe pain \\
\hline $\mathrm{N}$ & 7 & 74 & 83 & 49 & 8 \\
\hline NDI & $22.0(18.0 ; 37.8)$ & $30.0(23.5 ; 38.0)$ & $36.0(26.7 ; 46.0)$ & $56.0(43.1 ; 69.4)$ & $61.0(51.7 ; 79.0)$ \\
\hline NPQ & $22.2(11.1 ; 33.3)$ & $33.3(25.0 ; 41.7)$ & $38.9(32.1 ; 50.0)$ & $55.5(42.7 ; 69.1)$ & $55.5(44.6 ; 74.1)$ \\
\hline COM & $2.0(1.6 ; 3.1)$ & $2.6(2.2 ; 3.0)$ & $2.6(2.4 ; 3.1)$ & $3.4(2.7 ; 3.8)$ & $3.2(3.0 ; 3.7)$ \\
\hline
\end{tabular}

*: Values are given as median (P25, P75). NDI and NPQ scores are given as \% (range 0-100). COM scores are given as points (range I-5).

Effect size of NDI, NPQ and COM for patients having worsened, not changed or improved according to external criteria for pain and disability are shown in Tables 7 and 8. As seen in those tables, the effect sizes of NDI and NPQ are consistent in showing moderate improvements in patients having actually improved according to the external criterion, while the effect size of COM magnifies the amount of that improvement. As to patients reporting to have actually worsened, the effect size of NDI shows a small change consistent with that external criterion, while the one of NPQ is close to the cut-off point for small change and the COM does not detect any change. The same trends are observed for results on pain (Table 6).

Tables 7 and 8 show correlation among the scores of the VAS for NP, VAS for referred pain, NDI, COM and NPQ, CSQ, and SF-12 (Physical and Mental). As seen in those tables, on days 1 and 15 correlations among NDI, NPQ, COM, VAS, CSQ. PCS-SF12 and MCS-SF12 (Physical and Mental) were significant at the $\mathrm{p}<0.001$ level, except for the one between MCS-SF12 and VAS for referred pain on day 1, and MCS-SF12 and PCS-SF12 on days 1 and 15. Correlations of NDI and NPQ with the rest of the scales were similar and consistently stronger than correlations of COM. Correlations between NDI and NPQ were 0.84 on day 1 and 0.91 on day 15, whereas correlations between COM and NPQ were 0.63 on day 1 and 0.71 on day 15 .

\section{Discussion}

Results from this study show that the Spanish versions of both NDI and COM are comprehensible and appropriate instruments. In addition, they show that NDI, NPQ and COM are internally consistent and valid instruments to measure neck pain patients' disability, that floor and ceiling effects are not a major concern for any of those questionnaires and that they can be used in routine clinical conditions. In fact, this study was performed in routine conditions, no patient left the NDI and NPQ questionnaires unanswered, and only 4 out of $221(1.8 \%)$ left the COM unanswered (Table 2).

According to results from this study, NDI is more effective than NPQ and COM to assess neck pain disability. It is reliable and shows the highest correlations with results from instruments to measure pain, disability and quality of life. In addition, it is the only questionnaire for which the evolution of its score is consistent with external criteria for pain and disability (Tables 4 and 5) and for which effect sizes for pain and disability are consistent with patients' assessment of their own clinical evolution (Table 6). According to these results, NPQ is the second best and COM is the worst. NPQ does not detect worsening in disability and it suggests pain improvement in patients denying such an improvement (Table 6). Although internal validity is similar for all the questionnaires and differences in correlation and reliability are small, COM is less reliable than NDI, and its correlations with all the other scales and questionnaires are lower than those for both NDI and NPQ. In addition, COM is insensitive to worsening for both pain and disability, it reflects improvement in pain for patients denying any change, and it magnifies the amount of improvement for pain and, especially, disability (Table 6). This implies that using the COM may lead to the evolution of patients appearing to be more positive than it actually is. The inferiority of COM to assess pain and disability may be due to its global score being influenced by patients' assessment of function, well being, absenteeism and satisfaction, as opposed to the scores of NDI and NPQ, which only focus on pain and disability.

Filling out the NDI requires two minutes more than answering the COM. However, both questionnaires can be appropriately filled out by the patient in the waiting room without assistance, so this aspect is not a major

Table 5: Values of NDI, NPQ and COM across categories for external criteria for disability*

\begin{tabular}{|c|c|c|c|c|c|}
\hline External criterion for disability* & No disability & Mild & Moderate & Severe & Very severe \\
\hline $\mathrm{N}$ & 7 & 56 & 82 & 59 & 16 \\
\hline NDI & $18.0(12.0 ; 46.0)$ & $27.3(20.0 ; 35.5)$ & $40.0(28.0 ; 47.0)$ & $44.0(30.0 ; 60.0)$ & $70.5(58.5 ; 76.0)$ \\
\hline NPQ & $22.2(13.9 ; 41.7)$ & $30.5(25.0 ; 37.1)$ & $38.9(33.3 ; 53.1)$ & $47.2(38.9 ; 62.5)$ & $69.0(54.8 ; 77.1)$ \\
\hline COM & $2.4(1.6 ; 2.6)$ & $2.5(2.0 ; 2.9)$ & $2.7(2.4 ; 3.2)$ & $3.0(2.6 ; 3.7)$ & $3.6(3.1 ; 4.0)$ \\
\hline
\end{tabular}

*: Values are given as median (P25, P75). NDI and NPQ scores are given as \% (range 0-100). COM scores are given as points (range I-5). 
Table 6: Effect size of NDI, NPQ and COM for patients having worsened, not changed or improved between days I and I6, according to external criteria for pain and disability.

\begin{tabular}{|c|c|c|c|c|c|}
\hline Scale & Patients' status according to external criterion for disability & $N^{*}$ & Mean & SD & Effect Size ${ }^{* *}$ \\
\hline \multirow[t]{3}{*}{ NDI } & Worsened & 29 & -4.34 & 17.98 & -0.24 \\
\hline & Unchanged & 80 & 2.46 & 16.07 & 0.15 \\
\hline & Improved & 111 & 12.20 & 18.52 & 0.66 \\
\hline \multirow[t]{3}{*}{ NPQ } & Worsened & 29 & -2.58 & 18.13 & -0.14 \\
\hline & Unchanged & 80 & 1.02 & 16.18 & 0.06 \\
\hline & Improved & 111 & 11.69 & $|7.5|$ & 0.67 \\
\hline \multirow[t]{3}{*}{ COM } & Worsened & 26 & 0.04 & 0.89 & 0.05 \\
\hline & Unchanged & 79 & 0.13 & 0.70 & 0.19 \\
\hline & Improved & 106 & 0.63 & 0.69 & 0.92 \\
\hline Scale & Patients' status according to external criterion for pain & $\mathrm{N}^{*}$ & Mean & SD & Effect Size ${ }^{* *}$ \\
\hline \multirow[t]{3}{*}{ NDI } & Worsened & 35 & -4.05 & 16.21 & -0.25 \\
\hline & Unchanged & 82 & 4.02 & 17.54 & 0.13 \\
\hline & Improved & 103 & 12.01 & 17.96 & 0.67 \\
\hline \multirow[t]{3}{*}{ NPQ } & Worsened & 35 & -5.17 & 19.36 & -0.27 \\
\hline & Unchanged & 82 & 3.21 & 17.02 & 0.19 \\
\hline & Improved & 103 & 11.86 & 16.57 & 0.72 \\
\hline \multirow[t]{3}{*}{ COM } & Worsened & 32 & -0.02 & 0.75 & -0.02 \\
\hline & Unchanged & 78 & 0.25 & 0.66 & 0.38 \\
\hline & Improved & 101 & 0.60 & 0.75 & 0.79 \\
\hline
\end{tabular}

*: Total number of patients participating in the study was 22I. Missing patients in these tables are due to missing values in either the questionnaire (NDI, NPQ or COM) or the external criterion for pain or disability

*** Absolute values for effect size should be interpreted as follows: values $<0.20$ correspond to no change, $0.20-0.49$ to a small change, 0.50 to 0.79 to a moderate change and $\geq 0.80$ to a great change..$^{21-23}$

shortcoming for its use in routine practice. The time needed to score the questionnaires was not measured in this study, but physicians' feeling is that it is roughly similar for all of the questionnaires: NDI and NPQ are longer but scoring the COM is more complex, since it requires the reversal of the order of answers to questions No. 3 and
6 , and to calculate the mean value of the answers to the 7 items in order to get the final score.

Those characteristics may help to select the questionnaire that is most suitable for use in a particular setting. Whenever possible, the NDI seems to be the best option, especially in research settings where reliability, validity,

Table 7: Spearman Correlation Coefficients between NDI, COM, NPQ, VAS, CSQ, and SF-I 2 (Day I).

\begin{tabular}{|c|c|c|c|c|c|c|c|}
\hline & VAS (referred pain) & CSQ & NDI & NPQ & $\begin{array}{l}\text { Physical Component Summary } \\
\text { (PCS-12) }\end{array}$ & $\begin{array}{l}\text { Mental Component Summary } \\
\text { (MCS-12) }\end{array}$ & COM \\
\hline VAS (NP) & 0.485 & 0.403 & 0.480 & 0.47 I & -0.246 & -0.221 & 0.356 \\
\hline$P$ & 0.000 & 0.000 & 0.000 & 0.000 & 0.000 & 0.001 & 0.000 \\
\hline$N$ & 221 & 218 & 221 & 221 & 215 & 215 & 217 \\
\hline VAS (referred pain) & & 0.392 & 0.358 & 0.442 & $-0.43 I$ & $-0.08 I$ & 0.459 \\
\hline $\mathrm{P}$ & & 0.000 & 0.000 & 0.000 & 0.000 & 0.238 & 0.000 \\
\hline $\mathrm{N}$ & & 218 & 221 & 221 & 215 & 215 & 217 \\
\hline CSQ & & & 0.482 & 0.452 & -0.302 & -0.369 & 0.369 \\
\hline $\mathrm{P}$ & & & 0.000 & 0.000 & 0.000 & 0.000 & 0.000 \\
\hline $\mathrm{N}$ & & & 218 & 218 & 214 & 214 & 214 \\
\hline NDI & & & & 0.844 & -0.404 & -0.498 & 0.610 \\
\hline $\mathrm{P}$ & & & & 0.000 & 0.000 & 0.000 & 0.000 \\
\hline$N$ & & & & 221 & 215 & 215 & 217 \\
\hline NPQ & & & & & -0.458 & -0.402 & 0.628 \\
\hline $\mathrm{P}$ & & & & & 0.000 & 0.000 & 0.000 \\
\hline$N$ & & & & & 215 & 215 & 217 \\
\hline $\begin{array}{l}\text { Physical Component Summary } \\
\text { (PCS-12) }\end{array}$ & & & & & & -0.118 & -0.477 \\
\hline$P$ & & & & & & 0.085 & 0.000 \\
\hline$N$ & & & & & & 215 & 212 \\
\hline $\begin{array}{l}\text { Mental Component Summary } \\
\text { (MCS-I2) }\end{array}$ & & & & & & & -0.379 \\
\hline$P$ & & & & & & & 0.000 \\
\hline$N$ & & & & & & & 212 \\
\hline
\end{tabular}


Table 8: Spearman Correlation Coefficients between NDI0, COM, NPQ, VAS, CSQ, and SF-I2 (Day I5).

\begin{tabular}{|c|c|c|c|c|c|c|c|}
\hline & VAS (referred pain) & CSQ & NDI & NPQ & $\begin{array}{l}\text { Physical Component Summary } \\
\text { (PCS-12) }\end{array}$ & $\begin{array}{l}\text { Mental Component Summary } \\
\text { (MCS-12) }\end{array}$ & COM \\
\hline VAS (NP) & 0.519 & 0.584 & 0.697 & 0.699 & -0.458 & -0.274 & 0.610 \\
\hline$P$ & 0.000 & 0.000 & 0.000 & 0.000 & 0.000 & 0.000 & 0.000 \\
\hline $\mathrm{n}$ & 221 & 219 & 221 & 221 & 214 & 214 & 215 \\
\hline VAS (referred pain) & & 0.384 & 0.468 & 0.489 & -0.427 & -0.170 & 0.458 \\
\hline $\mathrm{P}$ & & 0.000 & 0.000 & 0.000 & 0.000 & 0.013 & 0.000 \\
\hline $\mathrm{n}$ & & 219 & 221 & 221 & 214 & 214 & 215 \\
\hline CSQ & & & 0.667 & 0.669 & -0.536 & -0.357 & 0.567 \\
\hline $\mathrm{P}$ & & & 0.000 & 0.000 & 0.000 & 0.000 & 0.000 \\
\hline $\mathrm{n}$ & & & 219 & 219 & 212 & 212 & 213 \\
\hline NDI & & & & 0.908 & -0.574 & -0.409 & 0.693 \\
\hline $\mathrm{P}$ & & & & 0.000 & 0.000 & 0.000 & 0.000 \\
\hline $\mathrm{n}$ & & & & 221 & 214 & 214 & 215 \\
\hline NPQ & & & & & -0.611 & -0.380 & 0.706 \\
\hline $\mathrm{P}$ & & & & & 0.000 & 0.000 & 0.000 \\
\hline $\mathrm{n}$ & & & & & 214 & 214 & 215 \\
\hline $\begin{array}{l}\text { Physical Component Summary } \\
\text { (PCS-12) }\end{array}$ & & & & & & -0.046 & -0.594 \\
\hline$P$ & & & & & & 0.503 & 0.000 \\
\hline $\mathrm{n}$ & & & & & & 214 & 210 \\
\hline $\begin{array}{l}\text { Mental Component Summary } \\
\text { (MCS-12) }\end{array}$ & & & & & & & -0.326 \\
\hline $\mathrm{P}$ & & & & & & & 0.000 \\
\hline $\mathrm{n}$ & & & & & & & 210 \\
\hline
\end{tabular}

sensitivity to changes and getting results that match actual patients' perceptions are essential concerns. In addition, the NDI is already available in several languages [6-10], and considering one questionnaire as an international standard could boost the implementation of disability assessment of neck pain patients as a routine procedure in clinical practice, and would help to compare results in studies conducted in different settings. However, since it might be better to use the COM than not to assess NPrelated disability at all, this questionnaire might also be an option to consider in clinical environments where saving two minutes in the waiting room may make a difference. However, users of the COM should be aware that the results they will get are likely to overestimate patients' improvement and may not detect actual worsening.

Reliability was measured in the pilot study on the same day, by giving the patient two different versions of the NDI and COM questionnaires. The interval after which the second version is to be given is a relevant decision; a too long interval may underestimate reliability by allowing actual changes in patients' degree of disability to occur, while a too short interval may overestimate it because of recall bias. At the design phase, it was decided to give both versions on the same day, and to implement measures to prevent recall bias. To that end, an interval of at least 30 minutes lapsed between both tests, and the patients were asked to fill out the VAS, NPQ, CSQ and SF12 questionnaires in the meantime. In addition, the second version of both questionnaires had a different name at the top ("NID" instead of "NDI", "CSC6" instead of "COM"), the first version was taken once answered and before handing out the second one, and both versions listed the questions in a different order. Although the change in the order of the questions might alter the results, because a patient may consider a previous question when answering the next, it was felt that this risk was worthwhile in order to avoid recall bias. This method for testing reliability had previously proven feasible and valid in our environment [29-31]. In fact, none of the patients identified the NDI and the NID, or the COM and the CSC6, as being the same, suggesting that the measures undertaken to avoid recall bias worked well. In addition, in spite of the potential effect of the different order of the questions in the NID and CSC6, intraclass correlation coefficients, kappa values and results from the Bland-Altman method showed a good reliability for NDI and COM. Therefore, the reliability of these questionnaires should not be a concern.

In some previous studies, patients' subjective classification of their clinical evolution during the study period has been used as the external criterion [32-36]. That approach makes sense in studies where patients' subjective perception of evolution is to be considered the "gold standard", such as those focusing on estimating the size of minimal clinically important changes (MCIC) [32-36]. However, it requires for patients to compare their current state at the end of the study period with their recall of the initial one, which is controversial [32,33]. At the design phase, it was felt that such an approach might not be the most suitable for this study, since relying on patients' memory might have led to identifying only those changes that would have been clinically meaningful for patients, and there- 
fore to underestimate the validity of the questionnaires that were being assessed. For that reason, in this study, patients' subjective classification of their current level of pain and disability at each assessment was used as the external criterion, and it was used to assess their matching with the scores on the NDI, NPQ and COM at that very moment (Tables 4 and 5). Consequently, to assess responsiveness to change, the change in scores of NDI, NPQ and COM from baseline to final assessment was explored for patients whose pain and disability had improved, remained unchanged or worsened according to their subjective classification at those assessments (Table 6).

For the NDI and NPQ, scores of items not applicable in one particular patient (e.g., driving or reading) are homogeneously distributed among the other dimensions. From the theoretical point of view, this might question the validity of comparisons among patients in which different dimensions are applicable. However, this is a common feature in the Oswestry Disability Index (ODI), from which both questionnaires derive, and previous studies have shown those questionnaires to be valid and reliable $[3,4,14]$.

The representativity of the sample is not a major concern. Participants were recruited in 9 different Spanish regions representing the entire cultural and economic spectrum of the country, both in the primary care and hospital setting, and the sample included acute, subacute and chronic patients with symptoms ranging from very mild to very severe (Tables 1 and 2).

The National Spanish Academy of the Language is a multinational agency integrated by both Castillian and Mexican experts in Spanish. It ensures that academic language, dictionaries, and semantic and grammatical rules are homogeneous throughout the Spanish speaking world. Therefore, these versions of the NDI and COM questionnaires may be used in any Spanish speaking country, although some minor finetuning may be necessary in order to adapt it to the specific terms that may be more commonly used in informal language in some specific cultural environments.

\section{Conclusion}

In conclusion, this study shows that the Spanish versions of both NDI and COM are comprehensible and reliable, that Spanish versions of NDI, NPQ and COM are internally consistent and valid, and that it is feasible to use any of those questionnaires in routine practice. In addition, they show that NDI is the most sensitive to change and the only questionnaire to reflect patients' evolution according to their own perception. This suggests that NDI is the best option to measure NP-related disability. It requires two more minutes than the COM to fill out, but it can be answered by the patient in the waiting room without assistance.

\section{Competing interests}

The author(s) declare that they have no competing interests.

\section{Authors' contributions}

FMK conceived the study and participated in its design, data collection, coordination and in the drafting of the manuscript. JB, JS and SG collaborated in coordination and data collection. AR, AM, VA, JZ and AC performed the statistical analysis and participated in the drafting of the manuscript. VA also participated in the design of the study. The rest of the authors of the study collaborated in its coordination and data collection. All authors revised the design, revised the draft manuscript and read and approved its final version.

\section{Additional material}

\section{Additional file 1}

Appendix 1. Spanish version of the NDI questionnaire. The translated and validated version of the Spanish NDI questionnaire.

Click here for file

[http://www.biomedcentral.com/content/supplementary/14712474-9-42-S1.doc]

\section{Additional file 2}

Appendix 2. Spanish version of the COM questionnaire. The translated and validated version of the Spanish COM questionnaire.

Click here for file

[http://www.biomedcentral.com/content/supplementary/1471-

2474-9-42-S2.doc]

\section{Additional file 3}

Bland \& Altman Method (NDI and COM). The figure represents a comparison of the scores of both versions of the NDI and COM questionnaires. Click here for file

[http://www.biomedcentral.com/content/supplementary/1471-

2474-9-42-S3.ppt]

\section{Acknowledgements}

This manuscript does not contain information about medical device(s).

This study was funded by the Kovacs Foundation.

The authors received no individual funding for their work.

The funding institution played no role in the study.

No benefits in any form have been or will be received from a commercial party related directly or indirectly to the subject of this manuscript. 


\section{References}

I. Cote P, Cassidy J, Carroll L: The Saskatchewan Health and Back Surgery Survery: the prevalence of neck pain and related disability in Saskatchewan. Spine 1998, 23:1689-98.

2. Kovacs FM, Abraira V, Zamora J, Gil del Real MT, Llobera J, Fernández $\mathrm{C}$, and the Kovacs-Atención Primaria Group: Correlation between pain, disability and quality of life in patients with common low back pain. Spine 2004, 29(2):206-2l 0.

3. Vernon H, Mior S: The Neck Disability Index: a study of reliability and validity. Journal of Manipulative and Physiological Therapeutics 1991, |4(7):409-4I5.

4. Leak AM, Cooper J, Dyer S, Williams KA, Turner-Stokes L, Frank AO: The Northwick Park Neck Pain Questionnaire, devised to measure neck pain and disability. $\mathrm{Br} J$ Rheumatol 1994 33:469-74.

5. Fairbank JCT, Couper J, Davies JB, O'Brien JP: The Oswestry Low Back Pain Disability Questionnaire. Physiotherapy 1980, 66:27I-273

6. Wlodyka-Demaille S, Poiraudeau S, Catanzariti JF, Rannou F, Fermanian J, Revel M: French translation and validation of 3 functional disability scales for neck pain. Arch Phys Med Rehabil 2002 83:376-86.

7. Cook C, Richardson JK, Braga L, Menezes A, Soler X, Kume P, Zaninelli $M$ : Cross-cultural adaptation and validation of the Brazilian Portuguese version of the Neck Disability Index and Neck Pain and Disability Scale. Spine 2006, 3 I:I62 I-I627.

8. Lee H, Nicholson LL, Adams RD, Maher CG, Halaki M, Bae SS: Development and psychometric testing of Korean language versions of $\mathbf{4}$ neck pain and disability questionnaires. Spine 2006, 3 I: | $84 \mid-1845$

9. Bicer A, Yazici A, Camdeviren H, Erdogan C: Assessment of pain and disability in patients with chronic neck pain: reliability and construct validity of the Turkish version of the neck pain and disability scale. Disabil Rehabil 2004, 26:959-962.

10. Ackelman B, Lindgren U: Validity and reliability of a modified version of the neck disability index. J Rehabil Med 2002 34:284-7.

II. Deyo R, Battie M, Beurskens A, Bombardier C, Croft P, Koes B, Malmivaara A, Roland M, Von Korff M, Waddell G: Outcome measures for low back pain research. Spine 1998, 23:2003-I3.

12. White $P$, Lewith $G$, Precott $P$ : The core outcomes for neck pain: Validation of a new outcome measure. Spine 2004, 29: 1923-30.

13. Rebbeck TJ, Refshauge KM, Maher CG, Stewart M: Evaluation of the Core Outcome Measure in Whisplash. Spine 2007, 32:696-702.

14. González T, Balsa A, Sáinz de Murieta J, Zamorano E, González I, Mar tín-Mola E: Spanish version of the Northwick Park neck pain questionnaire: Reliability and validity. Clin Exp Rheumatol 2001 19:41-46.

15. Kovacs FM, Abraira V, Zamora J, Fernández C, and the Spanish Back Pain Research Network: The transition from acute to subacute and chronic low back pain. A study based on determinants of quality of life and prediction of chronic disability. Spine 2005, 30(15): I786-1792.

16. Merskey H, Bogduk N: Description of chronic pain syndromes and definitions of pain terms. In Classification of chronic pain 2 nd edition. IASP press, Seattle WA; 1994.

17. Huskisson EC: Measurement of pain. Lancet 1974, 2: I I27-II3I.

18. Gandek B, Ware JE, Aaronson NK, Apolone G, Bjorner JB, Brazier JE, Bullinger M, Kaasa S, Leplege A, Prieto L, Sullivan M: Cross validation of items selection and scoring for the SF-I 2 health survey in nine countries: Results from the IQOLA project. J Clin Epidemiol I 998, 5 I ( I I): I I7I- I I78.

19. Rosenstiel AK, Keefe FJ: The use of coping strategies in chronic low back pain patients: relationship to patient characteristics and current adjustment. Pain 1983, 1 7:33-44.

20. Rodríguez L, Cano FJ, Blanco A: Evaluación de las estrategias de afrontamiento del dolor crónico. Actas Esp Psiquiatr 2004, 32(2):82-91

21. Bartko J]: The intraclass correlation coefficient as a measure of reliability. Psychol Rep 1966, 19:3-II.

22. Sprangers MA, Moinpour CM, Moynihan TJ, Patrick DL, Revicki DA, Clinical Significance Consensus Meeting Group: Assessing meaningful change in quality of life over time: a users' guide for clinicians. Mayo Clin Proc 2002, 77(6):56I-7I.
23. Guyatt G, Walter S, Norman G: Measuring change over time: assessing the usefulness of evaluative instruments. J Chronic Dis 1987, 40(2): $171-8$

24. Kazis LE, Anderson J], Meenan RF: Effect sizes for interpreting changes in health status. Med Care 1989, 27(3 Suppl):SI78-89.

25. Bland JM, Altman DG: Statistical methods for assessing agreement between two methods of a clinical measurement. Lancet 1986, I:307-10.

26. Fleiss JL, Cohen J: The equivalence of weighted kappa and the intraclass correlation coefficient as measures of reliability. Educ Psychol Meas 1973, 33:613-619.

27. Bland JM, Altman DG: Cronbach's alpha. BM] 1997, 3 | 4:572

28. Landis JR, Koch GG: The measurement of observer agreement for categorical data. Biometrics 1977, 33:159-174.

29. Kovacs FM, Llobera J, Gil del Real MT, Abraira V, Gestoso M, Fernández C, Kovacs Atención Primaria Group: Validation of the Spanish version of the Roland-Morris questionnaire. Spine 2002, 27:538-42.

30. Flórez MT, García MA, García F, Armenteros J, Alvarez A, Martínez MD: Adaptación transcultural a la población española de la escala de incapacidad por dolor lumbar de Oswestry. Rehabilitación 1995, 29(2): | 38-|45.

31. Kovacs FM, Muriel A, Abraira V, Medina JM, Castillo MD, Olabe J Spanish Back Pain Research Network: Psychometric characteristics of the Spanish version of the FAB Questionnaire. Spine 2006, 3 I (I): I04-I I0.

32. Kovacs FM, Abraira V, Royuela A, Corcoll J, Alegre L, Cano A, Muriel A, Zamora J, Gil del Real MT, Gestoso M, Mufraggi N: Minimal clinically important change for pain intensity and disability in patients with nonspecific low back pain. Spine in press.

33. Van der Roer N, Ostelo RWJG, Bekkering G, van Tulder MW, de Wet HCW: Minical clinically important change for pain intensity, functional status and general health status in patients with nonspecific low back pain. Spine 2006, 3 I :578-582.

34. Lee JS, Hobden E, Stiell IG, Wells GA: Clinically important change in the visual analog scale after adequate pain control. Acad Emerg Med 2003, I 0: I I 28-30.

35. Cepeda MS, Africano JM, Polo R, Alcala R, Carr DB: What decline in pain intensity is meaningful to patients with acute pain? Pain 2003, I 05:|5|-7.

36. Farrar JT, Young JP Jr, LaMoreaux L, Werth JL, Poole RM: Clinical importance of changes in chronic pain intensity measured on an I I-point numerical pain rating scale. Pain 200I, 94:149-58.

\section{Pre-publication history}

The pre-publication history for this paper can be accessed here:

http://www.biomedcentral.com/1471-2474/9/42/prepub

Publish with Biomed Central and every scientist can read your work free of charge

"BioMed Central will be the most significant development for disseminating the results of biomedical research in our lifetime. "

Sir Paul Nurse, Cancer Research UK

Your research papers will be:

- available free of charge to the entire biomedical community

- peer reviewed and published immediately upon acceptance

- cited in PubMed and archived on PubMed Central

- yours - you keep the copyright

BioMedcentral 